\title{
Formulação de políticas públicas: questões metodológicas relevantes
}

\author{
Carmen Rosario Ortiz G. Gelinski ${ }^{I}$ \\ Erni José Seibel ${ }^{2}$ \\ Universidade Federal de Santa Catarina
}

\section{Introdução}

\begin{abstract}
A
discussão sobre políticas públicas vem ganhando espaço nos últimos anos em diversos fóruns. Tanto no âmbito dos cursos de Pós-graduação em Ciências Sociais (ANPOCS) quanto dos Encontros de Sociedade de Economia Política (SEP) e da Associação Brasileira de Ciência Política $(\mathrm{ABCP})$, o assunto ganhou relevância com a constituição de grupos de trabalho ou mesas temáticas.

Não que a discussão dos temas ligados à gestão das políticas públicas e sociais não estivesse sempre presente em diversas áreas e que não se tenha trabalhos clássicos na literatura da Ciência Política, da Sociologia ou mesmo da Economia e da Administração. Só que no caso do Brasil, o tema ganharia impulso no fim dos anos 80 , época em que estudos sobre a redemocratização do país e as novas formas de gestão do orçamento público - presentes na reforma constitucional de 1988 - viriam à tona.

Souza (2007) aponta três motivos que dariam maior visibilidade ao assunto no país. Em primeiro lugar, a adoção de políticas restritivas a gastos que seriam implementadas não apenas no Brasil, mas em boa parte dos países em desenvolvimento, desde os anos 90 . Elas motivariam toda uma série de estudos para melhorar o desenho e a gestão das políticas públicas. Em segundo lugar, com a substituição do arcabouço keynesiano pelas políticas restritivas a gastos, as políticas sociais passariam a ter um caráter focalizado ao invés de universal. E, em terceiro lugar, nos países com democracia recente-caso dos países latino americanos - as coalizões não teriam conseguido, ainda, definir como se da o equacionamento entre recursos e necessidades da população.
\end{abstract}

${ }^{1}$ Professora do Departamento de Economia da Universidade Federal de Santa Catarina e doutoranda em Sociologia Política pelo PPGSP/UFSC. Endereço para correspondências: Departamento de Sociologia e Ciência Politica, CFH/UFSC, Campus Universitário, Trindade, Florianópolis, SC, 88040-900.

2 Professor do Departamento de Sociologia e Ciência Política da Universidade Federal de Santa Catarina e coordenador do Núcleo Interdisciplinar em Politica Públicas da UFSC. 
No Brasil, o avanço dos estudos nessa área já pode ser considerado significativo, se for avaliado pelo número de livros, papers ou artigos disponíveis, tanto que já é possível dispor de levantamentos do "estado de campo" ou do "estado das artes" sobre políticas públicas que, a modo dos tradicionais surveys, possibilitam uma visão ampla da discussão brasileira sobre o tema (REIS, 2003; SOUZA, 2006 e 2007; FARIA, 2003; MELO, 1999).

As políticas públicas são ações governamentais dirigidas a resolver determinadas necessidades públicas. As políticas podem ser sociais (saúde, assistência, habitação, educação, emprego, renda ou previdência), macroeconômicas (fiscal, monetária, cambial, industrial) ou outras (científica e tecnológica, cultural, agrícola, agrária). Usualmente o ciclo das políticas é concebido como o processo de formulação, implementação, acompanhamento e avaliação.

Este trabalho - de caráter eminentemente exploratório - tem por interesse resgatar os estudos feitos sobre formulação de políticas públicas. Em particular, interessa saber como se formula uma política pública, quem decide, que instituições intervêm nos processos decisórios, de que forma questões ou problemas passam a fazer parte da agenda de políticas e qual a finalidade das políticas públicas. Esta versão não esgota a análise da literatura levantada ${ }^{3}$, mas trata-se de um primeiro esforço nesse sentido. A discussão pretende dar continuidade a trabalhos anteriores preocupados com a avaliação de políticas públicas (SEIBEL e GELINSKI, 2007) e com a possibilidade das demandas da sociedade civil sensibilizarem os gestores de políticas públicas (GELINSKI, 2007).

\section{Principais modelos de políticas públicas}

$\mathrm{Na}$ literatura recente sobre políticas públicas, dois textos merecem atenção no que se refere ao levantamento de modelos de formulação de políticas públicas. Trata-se dos textos de Celina Souza (2007) - Estado da arte da pesquisa em políticas públicas - e de Ana Cláudia Capella (2007) - Perspectivas teóricas sobre o processo de formulação de políticas públicas. Um terceiro texto, não tão recente mas que pode ser considerado clássico por balizar a discussão sobre o tema no país, é o artigo de Klaus Frey (2000)

\footnotetext{
${ }^{3}$ Os textos não citados de maneira direta, mas que fazem parte desse levantamento, encontram-se na seção Bibliografia adicional.
} 
Formulação de políticas públicas: questões metodológicas relevantes Carmen Rosario Ortiz G. Gelinski e Erni José Seibel

- Politicas públicas: um debate conceitual e reflexões referentes à prática da análise de políticas públicas no Brasil. A apresentação dos principais modelos, a serem arrolados aqui, tem por base principalmente esses textos.

\section{Tipo da política pública}

As reações e as expectativas das pessoas que serão impactadas por uma política pública estarão condicionadas à forma como é resolvido o conflito (ou provável conflito) dela decorrente. A partir dessa concepção, Lowi (apud FREY, 2000; SOUZA, 2007) classifica as políticas públicas em quatro tipos. O primeiro tipo - as políticas distributivas - é conformado por aquelas que beneficiam um grande número de pessoas, em escala relativamente pequena e com reduzido grau de conflito. O segundo são as políticas redistributivas, que impõem restrições ou perdas a determinados grupos, pelo qual tem um elevado grau de conflito. O terceiro tipo, as políticas regulatórias, são as que envolvem a burocracia, grupos de interesse na definição de ordens, proibições e regulamentações constitutivas, sendo que o seu grau de conflito vai depender da forma como se configura a política. Por último, as políticas constitutivas ou estruturadoras ditam as regras do jogo e definem as condições em que se aplicarão as políticas distributivas, redistributivas ou as regulatórias.

\section{Incrementalismo}

Os recursos públicos a serem destinados a programas ou ações públicas não partem do zero mas de “(...) decisões marginais e incrementais que desconsideram mudanças políticas ou mudanças substantivas nos programas governamentais" (SOUZA, 2007, p.73). Se por um lado este modelo perdeu sua força em países que executaram processos de reforma fiscal, por outro está presente em programas herdados de gestões anteriores e que por determinados constrangimentos não podem ser abandonados. ${ }^{4}$

\footnotetext{
${ }^{4}$ Cunha e Rezende (2005) apontam que é um desafio para a sociedade brasileira a tentativa de implementar mudanças no orçamento que venham lidar com as discrepâncias no país. Para isso, propõem dois tipos de ações. Do ponto de vista macro, via mobilização das lideranças da sociedade para os problemas do país e micro, no âmbito da organização pública para capacitar os técnicos para a elaboração de orçamentos menos incrementais.
} 


\section{ÜMANista de clinncias}

O ciclo da política pública-Policy Cycle

Tendo em vista o caráter dinâmico das políticas públicas, que podem sofrer modificações no processo de elaboração e implementação, Frey (2000, p.226) sugere a análise do ciclo político em cinco fases: (1) percepção e definição de problemas, (2) agenda setting, (3) elaboração de programas e decisão, (4) implementação de políticas e, finalmente, (5) a avaliação de políticas e as correções que se fizerem necessárias. Com essa classificação, o autor avança, em termos conceituais, em relação às classificações (de três fases) tradicionalmente propostas para o ciclo: formulação, implementação e controle.

OModelo "lata de lixo" (Garbage Can) e Múltiplos Fluxos (Multiple Streams)

Literalmente este modelo considera como se as alternativas estivessem numa lata de lixo, com vários problemas e poucas soluções. O modelo desenvolvido por Cohen e colaboradores (1972) considera que os gestores adaptam os problemas às soluções disponíveis e por isso seria freqüente a prática de tentativa e erro para resolver situações que demandem resposta dos agentes públicos. (SOUZA, 2007). A anarquia e a pouca consistência das organizações públicas seria uma constante.

O caráter anárquico das organizações públicas é também patente no Modelo de Múltiplos fluxos de Kingdon (apud CAPELLA, 2007). Pela complexidade e quantidade de problemas com que lidam os formuladores de políticas públicas somente algumas delas serão consideradas na "agenda decisional", isto é a parte da agenda que contém soluções prontas. O Modelo de Múltiplos Fluxos de Kingdon, baseado no Modelo "lata de lixo", analisa os fluxos que percorre uma decisão em organizações que se configuram como "anarquias organizadas" (como universidades e governos nacionais), que operam sob incerteza e com alto grau de ambigüidade.

\section{Coalizão de defesa-Advocacy Coalition}

Este modelo, proposto por Sabatier e Jenkins-Smith (1993), é uma contraposição ao modelo do ciclo político e pelo garbage can por entender que eles têm pouca capacidade explicativa sobre as mudanças nas políticas públicas. 
Formulação de políticas públicas: questões metodológicas relevantes Carmen Rosario Ortiz G. Gelinski e Erni José Seibel

\begin{abstract}
Segundo esses autores, a política pública deveria ser concebida como um conjunto de subsistemas relativamente estáveis, que se articulam com os acontecimentos externos, os quais dão os parâmetros para os constrangimentos e os recursos de cada política pública (CAPELLA, 2007, p.75).
\end{abstract}

Para os autores deste modelo, elementos importantes (e ignorados pelos modelos anteriores) para entender os processos de formulação das políticas públicas são as crenças, os valores e as idéias. Uma determinada questão pode ser defendida por um grupo que partilha dessas crenças, valores ou idéias. Forma-se aí uma coalizão de defesa.

\title{
Arenas sociais-Policy Networks
}

Papel importante neste modelo será desempenhado pelas policy community, que tanto pode ser uma comunidade de especialistas, quanto pessoas com determinadas demandas. Essas pessoas "são cruciais para a sobrevivência e o sucesso de uma idéia, ou para colocar o problema na agenda pública" (CAPELLA, 2007, p.76). Para agirem de modo coeso e terem sucesso nas suas demandas, constituem redes sociais que envolvem laços, vínculos e conexões. $O$ foco deste modelo de formulação de políticas públicas não está nas características das redes e sim nas relações, vínculos e trocas que se estabelecem entre entidades e indivíduos, (CAPELLA, 2007).

Como aponta Frey (2000), não se trata de relações sociais institucionais, com distribuição de papéis. São relações mais informais, mas que permitem que se criem laços de confiança além de uma estrutura horizontal de competências, com grande densidade comunicativa entre os seus membros. Normalmente, são grupos que se reúnem ao redor de um assunto bem delimitado (reciclagem de lixo, criação de uma área de preservação ambiental) e não de políticas setoriais, como as políticas de saúde ou meio ambiente.

"Equilibrio interrompido" ou "pontuado"-Punctuated Equilibrium

A partir de princípios da biologia e da computação, Baumgartner e Jones (1999) desenvolvem o modelo de políticas públicas do Modelo de "equilíbrio interrompido" ou "pontuado". Nele, a política pública se caracteriza "(...) por longos períodos de estabilidade, interrompidos por períodos de instabilidade, que geram mudanças nas políticas anteriores" (SOUZA, 2007, p.77). 
Com o modelo é possível entender porque as políticas públicas podem passar por fases de manutenção do status quo, ou por fases com alterações significativas. "Nesse modelo, longos períodos de estabilidade, em que as mudanças se processam de forma lenta, incremental e linear, são interrompidos por momentos de rápida mudança (punctuations)" (CAPELLA, 2007, p.111). Isso explica por que certas idéias adquirem popularidade e se disseminam ocupando o lugar de questões que até esse momento eram centrais. Nesse modelo ocupa papel importante a construção de uma imagem da política pública proposta (policy image) e do contexto institucional que opera no processo de elaboração da imagem.

Modelos influenciados pelo "gerencialismo público" - politicas de caráter participativo

Sob influência do gerencialismo público (public management) e das políticas restritivas a gastos, as políticas públicas passariam a ser focadas na busca da eficiência. Souza (2007) menciona que além da eficiência, o fator credibilidade (regras claras) e a questão da delegação têm sido a tônica no desenho de políticas públicas. Os trabalhos nessa linha enfatizam questões como a eficiência e a racionalidade das políticas públicas via desregulamentação, privatização e reformas no sistema social.

No Brasil desde a década de 1990, em contraposição às análises de cunho mais gerencialista, há uma série de tentativas de adotar políticas de cunho mais participativo, em obediência a reformas constitucionais. Elas instituiriam novas formas de incorporar os segmentos da sociedade na formulação das políticas públicas, via conselhos gestores de políticas públicas (de saúde, de assistência social, de trabalho, de segurança, e outros). A esses espaços soma-se a proposta de partidos políticos de submeter a decisão popular o destino de parcela dos recursos - o orçamento participativo.

A intenção, como aponta Teixeira (2008), era criar espaços em que setores organizados, como sindicatos e movimentos populares e sociais tivessem voz. A inclusão desses elementos no processo político, ia além de criar uma nova categoria que participasse das decisões políticas. Acreditava-se que por meio desses mecanismos poderia se universalizar o acesso aos serviços e com isso diminuir as desigualdades sociais. 
Formulação de políticas públicas: questões metodológicas relevantes Carmen Rosario Ortiz G. Gelinski e Erni José Seibel

A despeito dos sucessos ou insucessos dessa empreitada ${ }^{5}$, o que se quer destacar aqui, é que esse novo formato da elaboração das políticas públicas pode ser considerado um divisor de águas na análise das políticas públicas brasileiras. As análises feitas após os anos 1990 com certeza passam por algum tipo de avaliação da nova institucionalidade.

\section{Aspectos levados em consideração na formulação de políticas públicas}

Conforme visto na seção anterior, há todo um conjunto de estudos sobre formulação de políticas públicas. Apesar das suas diferenças e dos contextos em que tenham sido elaborados há elementos teóricos comuns que podem possibilitar uma reflexão sobre a formulação das políticas públicas. Nesta seção algumas dessas questões serão resgatadas. Em primeiro lugar, a discussão sobre a concepção do Estado que perpassa as políticas públicas. Em segundo lugar, quem elabora as políticas públicas, isto é quem são os policy makers, a importância das redes e das arenas, e como é definida a agenda e que assuntos ou questões passam a fazer parte dela.

\section{Concepção do Estado}

O conteúdo ou agenda das políticas públicas dependerá, em primeira instância, da concepção do Estado por parte daqueles que elaboram as políticas públicas. O que está em jogo é elucidar quem define o público alvo de uma política pública. Santos e colaboradores (2007, p.83) advertem "elaborar uma política pública significa definir quem decide o quê, quando, com que consequiências e para quem".

Interessa inicialmente elucidar o que quer dizer esse caráter de "público"? Elas devem apenas promover equidade, saúde ou educação ou também deveriam estar destinadas a promover e aperfeiçoar o funcionamento do mercado?

Órgãos de classe ligados aos setores empresariais advogam por políticas públicas que promovam a iniciativa privada. Exemplo disso pode ser visto ao se ler os objetivos da área de Políticas Públicas do SEBRAE/CE, instituição de apoio a empresas de pequeno e médio porte.

\footnotetext{
${ }^{5}$ Para uma revisão crítica dos avanços e recuos das formas de participação cidadã nas políticas públicas, ver: Teixeira (2008), Avritzer (2003), Borba e Lüchmann (2006), Côrtes (2002, 2007), Lüchmann (2002), Wrampler (2003) e Tatagiba (2002).
} 
E mais, independente do porte das empresas esta poderia ser, sem dúvida, a pauta de reivindicações de qualquer entidade empresarial.:

- Atuar junto aos poderes na construção de ambiente que favoreça o surgimento e fortalecimento das microempresas e empresas de pequeno porte, articulando a elaboração de leis que incentivem e assegurem maior participação deste segmento na economia;

- Promover ações junto aos governos federal, estadual e municipal objetivando a inserção das microempresas e empresa de pequeno porte em suas políticas de desenvolvimento;

- Buscar tratamento diferenciado às microempresas e empresas de pequeno porte, através da simplificação de suas obrigações administrativas, tributárias, previdenciárias e creditícias, visando a ampliar suas condições de sobrevivência e competitividade;

- Analisar e acompanhar os atos normativos do poder executivo e órgãos da administração pública, bem como a tramitação de instrumentos legislativos (projetos de lei, medidas provisórias, propostas de emendas à constituição) que afetam as microempresas e empresa de pequeno porte nas esferas federal, estadual e municipal. (SEBRAE/ CE, 2008, p.1).

Crítica severa é feita por Santos e colaboradores (2007) a essa concepção de políticas públicas. Para eles, iniciativas dessa natureza não poderiam ser denominadas de "políticas públicas" haja vista que o seu objetivo seria favorecer a classe dominante. Para os autores, mesmo as políticas de cunho social têm essa finalidade por funcionarem como paliativo, ou por refrearem a ação da população excluída. Também negam o caráter de "público" a essas políticas pois não são fruto de um processo democrático de decisão.

No que se refere à formulação de políticas sociais a concepção do Estado que tiverem os policy makers determinará se as políticas propostas terão que obedecer a limitações orçamentárias coerentes com a existência de um Estado mínimo ou se, ao contrário, as questões sociais serão peças fundamentais para conduzir a estados de bem-estar social ${ }^{6}$.

\footnotetext{
- Nesta linha de discussão se coloca toda a literatura sobre modelos de bem-estar social. Ver ao respeito, Arretche (1995), Esping-Andersen (1995) Gomes (2006) e Seibel e Gelinski (2007).
} 
Agenda Setting e Policy Makers

O que determina que uma questão passe a ter relevância a ponto de ser incluída na agenda? Como uma questão se torna relevante? Quem elabora as políticas públicas?

De acordo com Camargo (2004), a estruturação dos programas sociais e, portanto, a definição das políticas públicas deve estar alicerçada nos objetivos que os programas sociais pretendam atender. Redução de índices de pobreza, criação de redes de proteção social, queda de analfabetismo, ou melhoria das condições de saúde são apenas alguns dos elementos que poderiam nortear as políticas públicas. Para Camargo, a escolha dos programas depende fundamentalmente de três fatores: volume de recursos, definição de prioridades e geração de incentivos. $\mathrm{O}$ montante de recursos e as prioridades estabelecidas é que definirão a abrangência das políticas, isto é se serão focalizadas ou de caráter universal. As questões que se colocam são: como são definidas essas prioridades? E quem as define?

No modelo de Punctuated equilibrium, algumas idéias tornam-se populares, em detrimento de outras. A mudança de agenda deve ser creditada a o que Baumgartner e Jones (1999) chamam de feedback positivo, que eleva o grau de importância de certas questões e gera um efeito cascata que desloca algumas idéias do seu pedestal. Cabe um lugar de destaque ao poder da mídia na possibilidade de pôr em evidência uma idéia. O papel da mídia também é destacado por Frey (2000, p.227), na análise do ciclo político (policy cicle): "Freqüentemente são a mídia e outras formas de comunicação política e social que contribuem para que seja atribuída relevância política a um problema peculiar".

No Modelo de Múltiplos Fluxos de Kingdon (apud Capella, 2007) uma questão passa a fazer parte da agenda (agenda setting) quando há uma junção dos três fluxos do modelo (fluxo de problemas, fluxo de soluções e fluxo política) e encontra-se aberta uma janela política (policy window), nome dado às oportunidades que se abrem em situações de mudanças no governo, ou em determinadas fases do ciclo orçamentário. Nessas circunstâncias, exercem um papel muito importante os empreendedores de políticas (os policy entrepreneurs), aqueles dispostos a investir numa idéia, que tanto podem ser elementos da própria burocracia, como parlamentares, grupos de interesse ou membros da academia. 


\section{HÜMANAS}

O papel desses empreendedores, que constituem a policy community, é fundamental para garantir a sobrevivência de uma idéia, ou para colocá-la na agenda pública. Souza (2007) menciona três mecanismos que podem chamar a atenção dos formuladores de políticas públicas: (a) tornar públicos indicadores que mostrem a dimensão do problema; (b) eventos que mostrem como a situação se repete ou é decorrente de desastres e (c) o retorno ( feedback) das políticas em vigor, que mostram a necessidade de correções.

Para Gaetani (1997), as demandas, que posteriormente farão parte de agenda de políticas públicas, podem ter origem em quatro segmentos: na sociedade civil, na esfera política, na burocracia governamental ou, ainda, em setores externos que têm por função aportar recursos ao sistema. Dentre estes, o autor, destaca a importância que vem assumindo a sociedade civil organizada, que opera recursos de marketing institucional e tem consolidado as organizações não-governamentais no processo de formulação e implementação de políticas públicas.

Tendo definido as prioridades ou demandas, a fase da agenda setting é o momento em que se decide se um tema fará parte na pauta política. Essa decisão está ligada à avaliação dos custos e benefícios das opções disponíveis bem como uma avaliação para ver se a idéia tem chances de se impor na arena política (Frey, 2000). Aí passarão a ter papel fundamental os funcionários ou técnicos da organização administrativa do Estado.

Na nova arquitetura institucional, inaugurada pelos conselhos de políticas públicas pós Constituição Federal de 1988, cabe às partes (normalmente representantes do governo, da sociedade civil e dos usuários) propor as necessidades. Entretanto, como aponta Teixeira (2008), ao mesmo tempo em que os conselhos inauguraram novas formas de aproximar o Estado da sociedade civil, o que tem se visto de fato é que a incorporação da agenda nas políticas setoriais dependerá da vontade política dos governos e/ou do poder de pressão da sociedade civil ${ }^{7}$.

\section{Considerações finais}

Não há uma forma unívoca de se analisar as políticas públicas. Desde a concepção e formulação até o acompanhamento e a avaliação.

\footnotetext{
${ }^{7} \mathrm{Na}$ contramão da possibilidade dos gastos orçamentários serem direcionados pelas decisðes dos conselhos, Duchateu e Aguirre (2007) mostram que a alocação orçamentária entre 1999 e 2003 foi influenciada pela cooperação entre partidos ou entre integrantes de uma mesma base partidária.
} 
Questões de ordem técnica e política sem dúvida definirão a escolha dos procedimentos técnicos e metodológicos. Se por um lado, o fato de não ter metodologias universais para analisar as políticas públicas pode ser um pouco frustrante, ao se deparar com a tarefa de analisar uma dada política pública, por outro lado, a disponibilidade de várias opções metodológicas e questões em aberto, permitem que possam ser pensadas novas formas de enfrentar empreitadas dessa natureza.

No Brasil, das diretrizes emanadas da Constituição Federal de 1988 surgiria uma nova dinâmica para se elaborar políticas públicas. Isso obedecia à necessidade de lidar com a escassez de recursos orçamentários e, por essa via, a descentralização das políticas incorporaria outras esferas na gestão da escassez. Também, o desenho participativo obedecia aos anseios da sociedade brasileira de tomar decisões, num clima de restauração de direitos civis próprio do retorno à democracia.

Se essas experiências participativas podem ser consideradas "modelo" é assunto para um extenso debate que muitas vezes vem pintado de um claro matiz político-ideológico. Representa motivo para comemoração o fato dessas novas experiências, ao igual que todos os estudos de políticas públicas, terem gerado um volume significativo de estudos e pesquisas que, ao analisar as particularidades e os sucessos e insucessos de políticas e programas, permitem uma reflexão profunda que podem conduzir ao aprimoramento dessas práticas.

\section{Referências bibliográficas}

ARRETCHE, M.T.(1995). Emergência e Desenvolvimento do Welfare State: teorias explicativas. BIB, Rio de Janeiro, 39:3-40, 1995.

AVRITZER, L. O orçamento participativo e a teoria democrática: um balanço crítico. In: AVRITZER, L. \& NAVARRO, Z. (Orgs.). A inovação democrática no Brasil: o orçamento participativo. São Paulo: Cortez, 2003.

BAUMGARTNER, F.R. \& JONES, B.D. Punctuated equilibrium theory: explaining stability and change in American policymaking. In: SABATIER, P.A. Theories of the policy process. Oxford: Westview Press, 1999.

BORBA, J. \& LÜCHMANN, L.H.H.. Orçamento participativo: uma análise das experiências desenvolvidas em Santa Catarina. Florianópolis: Relatório de Pesquisa/UFSC, 2006. 
CAMARGO, J.M.. Política social no Brasil: prioridades erradas, incentivos perversos. São Paulo em Perspectiva, 18(2): 68-77, 2004.

CAPELLA, A.C. Perspectivas teóricas sobre o processo de formulação de políticas públicas. In: HOCHMAN, G.; ARRETCHE, M. \& MARQUES, E. Políticas públicas no Brasil. Rio de Janeiro: Editora FIOCRUZ, 2007.

COHEN, M.; MARCH, J. \& OLSEN, J. A garbage can model of organizational choice. Administrative Science Quarterly, 17: 1-25, 1972.

CÔRTES, S.M.V.Participação de usuários nos conselhos municipais de saúde e de assistência social de Porto Alegre. In: PERISSINOTTO, R. \& FUKS, M. Democracia: teoria e prática. Rio de Janeiro e Curitiba: Relume Dumará e Fundação Araucária, 2002.

CÔRTES, S.M.V. Viabilizando a participação em Conselhos de Política Pública Municipais: arcabouço institucional, organização do movimento populare policy communities. In: HOCHMAN, G; ARRETCHE, M. \& MARQUES, E. Políticas públicas no Brasil. Rio de Janeiro: Editora FIOCRUZ, 2007.

CUNHA, A. \& REZENDE, F. Orçamento e desenvolvimento. In: CAVALCANTI, B.S.; RUEDIGER, M.A. \& SOBREIRA, R. Desenvolvimento e construção nacional: políticas públicas. Rio de Janeiro, Editora FGV, 2005.

DUCHATEAU, P.V. \& AGUIRRE, B. Estrutura política como determinante dos gastos federais. Anais do XXXV ENCONTRO NACIONAL DE ECONOMIA - ANPEC, Recife, 4 a 7 de Dezembro de 2007.

ESPING-ANDERSEN, G. O futuro do Welfare State na nova ordem mundial. Lua Nova, 35, 1995.

FARIA, C.A.P. de. Idéias, conhecimento e políticas públicas: um inventário sucinto das principais vertentes analíticas recentes. Revista Brasileira de Ciências Sociais, 18(51): 21-30, 2003.

FREY, K. Políticas públicas: um debate conceitual e reflexões referentes à prática da análise de políticas públicas no Brasil. Planejamento e Políticas Públicas, Brasília, 21: 211-59, 2000.

GAETANI, F. Gestão e avaliação de políticas e programas sociais: subsídios para discussão. Textos para Discussão ENAP. Abril, 1997. 
Formulação de políticas públicas: questões metodológicas relevantes Carmen Rosario Ortiz G. Gelinski e Erni José Seibel

GELINSKI, C.R.O.G Até que ponto os gestores de políticas públicas são permeáveis ás demandas da sociedade civil? O caso daAssistência Social. Trabalho apresentado na disciplina Participação e Democracia, Programa de Doutoramento em Sociologia Política/UFSC. Texto mimeografado, Agosto de 2007.

GOMES, F.G. Conflito social e welfare state: Estado e desenvolvimento social no Brasil. Revista de Administração Pública, 40(2): 201-34, 2006.

LÜCHMANN, L.H.H. Os Conselhos Gestores de Políticas Públicas: desafios do desenho institucional. Ciências Sociais/Unisinos, 38 (161): 43-79, 2002.

MARQUES, R.M. \& MENDES, A. Servindo a dois senhores: as políticas sociais no governo Lula. Revista Katálysis, 10(1): 15-23, 2007.

MELO, M.A. Estado, governo e políticas públicas. In: MICELI, S. (Org.). O que ler na ciência social brasileira (1970-1995) - Volume 3: Ciência política. Pp. 59-100. São Paulo e Brasília: Sumaré, Anpocs e Capes, 1999.

REIS, E.P. Reflexões leigas para a formulação de uma agenda de pesquisa em políticas públicas. Revista Brasileira de Ciências Sociais, 18(51), 2003.

SABATIER, P.A. The Status and development of policy theory: a reply to hill. Policy Currents, 7(4): 1-10, 1997.

SANTOS, R.S.; RIBEIRO, E.M. \& GOMES, F.G. Compreendendo a natureza das políticas do Estado capitalista. Revista de Administração Pública, 41(5): 819-34, 2007.

SEBRAE/CE. Políticas Públicas. In: http://www.ce.sebrae.com.br/pagina/ (acesso: 22 de Fevereiro de 2008).

SEIBEL, E.J. \& GELINSKI, C.R. O.G. Concepção do Estado e escolha da metodologia de avaliação de políticas públicas. Anais do XII Encontro Nacional de Economia Política. São Paulo, 2007.

SOUZA, C. Políticas públicas: uma revisão da literatura. Sociologias, 16: 20-45, 2006.

SOUZA, C. Estado da arte da pesquisa em políticas públicas. In: HOCHMAN, G; ARRETCHE, M. \& MARQUES, E. Políticas públicas no Brasil. Rio de Janeiro: Editora FOCRUZ, 2007. 


\section{UMMANAS}

TATAGIBA, L. Os conselhos gestores e a democratização das políticas públicas. In: DAGNINO, E. (Org.). Sociedade civil e espaços públicos no Brasil. Pp. 13-32. Rio de Janeiro: Paz e Terra, 2002.

TEIXEIRA, AC. Até onde vai a participação cidadã? Le Monde Diplomatique Brasil, 2(7): 6-7, 2008.

WRAMPLER, B. Orçamento participativo: uma explicação para amplas variações nos resultados. In: AVRITZER, L. \& NAVARRO, Z. (Orgs.). $A$ inovação democrática no Brasil: o orçamento participativo. São Paulo: Cortez, 2003. 